\title{
EDITORIAL: A RESILIÊNCIA DAS INSTITUIÇÕES DE ENSINO SUPERIOR ANGOLANAS FACE AO IMPACTO DA COVID-19: UMA SÍNTESE DE MARÇO A DEZEMBRO DE 2020
}

\author{
Eurico Wongo Gungula ${ }^{1}$ \\ https://orcid.org/0000-0002-5685-1328
}

Com a publicação do Decreto Presidencial n. ${ }^{\circ}$ 81/20, de 25 de Março de 2020, que declarou o Estado de Emergência em todo o território nacional, com fundamento na situação de eminente calamidade pública, gerada pela acelerada transmissão do vírus Sars-Cov-2, foram publicados até 12 de Dezembro, com extensão até ao dia 10 de Janeiro de 2021, sete Decretos de situação de calamidade pública, que estabelecem, entre outras, medidas que visam evitar a propagação da COVID - 19 em todas as instituições de educação e ensino públicas, públicoprivadas e privadas.

As Instituições de Ensino Superior (IES) depararam-se com o desafio de conseguir materializar os seus objectivos estratégicos, definidos nos seus Planos de Desenvolvimento face aos constrangimentos resultantes da COVID - 19. Destaca-se a reinvenção que foi necessária e fundamental, no domínio do ensino presencial e à distância, da investigação científica, da extensão universitária, da gestão institucional e da internacionalização.

A aprovação, pelo Executivo Angolano, do Regulamento das Modalidades de Ensino a Distância e Semi-Presencial no Subsistema de Ensino Superior, através do Decreto Presidencial n. ${ }^{\circ}$ 59/20, de 3 de Março de 2020, revelou as fragilidades organizacionais de todas as IES, bem como a inércia das instituições encarregadas de assegurar e dinamizar o processo de melhoria da qualidade de ensino, da investigação científica e do desenvolvimento tecnológico.

Entre as principais fragilidades identificadas, destaca-se o facto de, até Fevereiro de 2020, não existir em Angola legislação aprovada sobre o funcionamento de cursos nas modalidades de ensino a distância e semi-presencial, aspecto que gerou inúmeras dificuldades para o pleno funcionamento das IES face ao impacto da COVID - 19, sobretudo nos primeiros meses da declaração do estado de calamidade pública.

A demora do Ministério de Tutela, na determinação de estratégias e de requisitos que viabilizassem o processo de ensino - aprendizagem nesta nova conjuntura de pandemia, foi outra das fragilidades com impacto directo na resiliência e reinvenção das distintas IES.

Nesta perspectiva, foram sintetizados, entre os requisitos determinados posteriormente pelo Ministério de Tutela, a disponibilização de materiais para cobrir o primeiro e segundo ano do curso a criar na modalidade de ensino a distância e semi-presencial; existência de docentes encarregues de orientar, supervisionar e avaliar o processo de ensino - aprendizagem; descrição das equipas de elaboração de materiais, indicação da qualificação e experiência profissional de cada um; existência de instalações físicas e tecnologias educativas específicas a utilizar, bem como a apresentação de comprovativos da avaliação positiva na modalidade de ensino presencial do curso que se pretende ministrar, na modalidade de ensino a distância ou semi-presencial.

Como se pode observar, a insuficiente preparação dos gestores, docentes e estudantes para lidar com as exigências do ensino a distância e semi-presencial em contextos de pandemia, reforçada pela escassez de materiais de biossegurança, pelo limitado acesso aos serviços de Internet, pela ausência de conteúdos digitalizados para a orientação de actividades académicas e científicas dos estudantes; pela limitada capacidade técnica e tecnológica para a dinamização e

${ }^{1}$ Universidade Óscar Ribas, Angola. Email: euricowongowongo@gmail.com 
realização de webinares, palestras, conferências, reuniões de trabalho, orientações metodológicas para docentes e pessoal administrativo, representam a síntese dos constrangimentos que geraram a suspensão das actividades académicas de Março a Setembro de 2020.

Não obstante, as experiências sistematizadas desde a declaração do Estado de Emergência em Angola, estimularam o desenvolvimento da capacidade de resiliência e adaptação geradas pela necessidade de continuar com a melhoria dos processos substantivos das IES, num contexto em que a transmissão do vírus Sars-Cov-2 continua a gerar discussões científicas, políticas e económicas a nível mundial, para a determinação de estratégias, procedimentos e vacinas, cada vez mais, eficazes, não só para travar e controlar o surgimento de novas variantes do vírus causador da pandemia da COVID - 19, mas também para a apropriação de conhecimentos para enfrentar situações similares que possam ocorrer no futuro e assim dar uma nova esperança à sobrevivência da espécie humana.

Assim, a equipa editorial da Revista SAPIENTIAE, na busca da melhoria da qualidade dos artigos seleccionados para o volume 6-2, apresenta temas internacionais variados.

O primeiro refere-se a "Problemas da história do tempo presente: Violência política, opinião pública e imprensa no México nos anos setenta", elaborado por Sérgio Arturo Sánchez Parra e Anderson Paul Gil Pérez, com o objectivo de analisar o processo de construção da opinião pública sobre a violência política no México, no início dos anos 1970. A metodologia utilizada é predominantemente qualitativa, apoiada no método histórico-crítico e na revisão por conjunturas de fontes documentais da imprensa, em particular do jornal El Sol de Sinaloa da Rede García Valseca.

O segundo trata de aspectos relacionados com a "Contabilidade administrativa: Ferramenta para tomar decisões em gestão", elaborado por Flor Isabel Salazar Vázquez, Jorge Herminio Gonzalez Urgiles, Paola Margoth Sanchez Salazar e Jonnathan Fabián Sanmartin Gonalez, com o propósito de ressaltar a análise da contabilidade administrativa, como ferramenta fundamental para oferecer, aos tomadores de decisão, informações ajustadas às suas reais necessidades. A metodologia utilizada é do tipo documental-descritiva. Entre os resultados obtidos, destaca-se a importância da contabilidade administrativa, que, apoiada na contabilidade de custos é capaz de oferecer informações contáveis, de grande valor, para subsidiar o processo de tomada de decisão.

O terceiro é uma abordagem sobre "Estado responsável e participação da segurança do cidadão na América Latina”, elaborada por Kleber Gabriel Guerrero Aray, Paola Estefanía Balseca Macías e Gabriela Rosana Guerrero Aray, com a finalidade de descrever o nível de violência existente na América Latina, considerada uma das regiões mais violentas e inseguras do planeta devido à falta de acesso a serviços básicos e à extrema pobreza, principalmente em países como: Brasil, Colômbia, México e Venezuela. Conclui-se que a América Latina exige a intervenção conjunta do Estado responsável e da participação dos cidadãos para a execução de programas de segurança dos cidadãos, a fim de se capacitar social e institucionalmente, para prevenir e controlar o crime no nível local e na região.

O quarto refere-se à "Economia política do regionalismo - Caso Angola e Namíbia", elaborado por Ezequiel Israel Jonas, com o propósito de desenvolver uma revisão teórica do regionalismo no quadro da economia política, de acordo com várias contextualizações que foram levantadas sobre este; tomando o caso de Angola e da Namíbia como uma expressão deste processo no continente Africano.

O quinto é uma abordagem sobre as "Representações sociais de adolescentes e jovens acerca da relação sexual e do uso do preservativo", feita por Bruno A. P. Dala, com o objectivo de conhecer as representações sociais sobre relação sexual e uso de preservativo em adolescentes e jovens. Concluiu-se que os adolescentes e jovens possuem informações sobre os perigos do não uso do preservativo, porém, para eles o uso de preservativo diminui o prazer sexual. 
O sexto trata de "Um cenário sobre a utilização de realidade virtual em uma instituição de ensino”, elaborado por Fábio Fonseca Barbosa Gomes e Éricles Alberto de Jesus Ribeiro, com o objectivo de identificar o que o público de uma instituição de ensino pensa sobre o uso de uma tecnologia de realidade virtual, visto que as suas aplicações são diversas, possuem um grande potencial de desenvolvimento e são aplicáveis em áreas distintas como a educação e saúde.

O sétimo é uma "Resenha do livro Fernández Dávalos, David (2020). Em voz alta: propostas para uma universidade comprometida com o seu tempo. México. Universidad Iberoamericana, A. C. Págs. 333.”, elaborada por José Javier Capera.

O oitavo é uma tradução de um livro sobre "Matemáticas aplicadas em cenários de crise COVID - 19" feita por Milagros Del Valle Morales Rangel, com o propósito de estudar os efeitos psicológicos, económicos e educativos sobre a população por um cenário de crise como a COVID - 19. As teorias matemáticas desenvolvidas neste ensaio são: Teoria do Caos, Cadeias de Markov e a Teoría de Nash.

O impacto que a COVID - 19 causou na população mundial pode medir-se a médio e longo prazo, através de mudanças no comportamento psicológico e nos hábitos sociais, de saúde, económicos e educativos. Este impacto deixará profundas marcas e dilemas morais tais como: que áreas devem ser priorizadas e qual será o esforço político dirigido a cada uma delas.

É neste enquadramento que o Conselho Editorial da Revista SAPIENTIAE convida a comunidade científica nacional e internacional a revisar os artigos publicados, assim como incentiva a submeter novas propostas para a possível publicação em futuras edições. 